ARTICLE

Received 25 Feb 2016 | Accepted 28 Apr 2016 | Published 9 Jun 2016

DOI: $10.1038 /$ ncomms11770

OPEN

\title{
Dynamic protein coronas revealed as a modulator of silver nanoparticle sulphidation in vitro
}

\author{
Teodora Miclăuş ${ }^{1}$, Christiane Beer ${ }^{2}$, Jacques Chevallier $^{3}$, Carsten Scavenius ${ }^{4}$, Vladimir E. Bochenkov ${ }^{1,5}$, \\ Jan J. Enghild ${ }^{4} \&$ Duncan S. Sutherland ${ }^{1}$
}

Proteins adsorbing at nanoparticles have been proposed as critical toxicity mediators and are included in ongoing efforts to develop predictive tools for safety assessment. Strongly attached proteins can be isolated, identified and correlated to changes in nanoparticle state, cellular association or toxicity. Weakly attached, rapidly exchanging proteins are also present at nanoparticles, but are difficult to isolate and have hardly been examined. Here we study rapidly exchanging proteins and show for the first time that they have a strong modulatory effect on the biotransformation of silver nanoparticles. Released silver ions, known for their role in particle toxicity, are found to be trapped as silver sulphide nanocrystals within the protein corona at silver nanoparticles in serum-containing cell culture media. The strongly attached corona acts as a site for sulphidation, while the weakly attached proteins reduce nanocrystal formation in a serum-concentration-dependent manner. Sulphidation results in decreased toxicity of Ag NPs.

\footnotetext{
${ }^{1}$ Interdisciplinary Nanoscience Center (iNANO), Aarhus University, Gustav Wieds Vej 14, 8000 Aarhus, Denmark. ${ }^{2}$ Department of Public Health, Aarhus University, Bartholins Alle 2, 8000 Aarhus, Denmark. ${ }^{3}$ Department of Physics, Aarhus University, Ny Munkegade 120, 8000 Aarhus, Denmark. ${ }^{4}$ Department of Molecular Biology and Genetics, Aarhus University, Gustav Wieds Vej 10, 8000 Aarhus, Denmark. ${ }^{5}$ Department of Chemistry, Lomonosov Moscow State University, Leninskie gory 1/3, 119991 Moscow, Russia. Correspondence and requests for materials should be addressed to D.S.S.

(email: duncan@inano.au.dk).
} 
$\mathrm{T}$ he biological effects of engineered nanomaterials as drug delivery vehicles or as unintentionally released nanoparticles (NPs) are of strong current interest. Biomoleculesmainly proteins-adsorbing at NPs modify their surface properties and are proposed as important modulators of particle-cell interactions $\mathrm{s}^{1-8}$. A pragmatic distinction has been made between the relatively easily studied, strongly attached proteins as longlived, hard coronas and the weakly attached, rapidly exchanging proteins as soft coronas ${ }^{9-13}$. The former are under focus with residence at the particles on timescales relevant for cellular binding and uptake ${ }^{4,6,14}$, whereas the role of the latter in modulating NP behaviour has yet to be established. Specific and different profiles of molecules concentrated within the hard corona at particles in biological media have been observed for different surface coatings ${ }^{15}$, charges ${ }^{16,17}$, sizes ${ }^{15,18}$ and shapes ${ }^{19}$. The concept of a biological identity imprinted within the protein corona and which determines NP-cellular interactions ${ }^{1-6}$ has been proposed ${ }^{20}$. Although the long-lived laver has been linked to particle aggregation ${ }^{19}$ and cell association ${ }^{6,14,21}$, the correlation of protein composition to cellular uptake/toxicity is still relatively weak $^{4,22,23}$. The involvement of soft corona in physical and/or chemical transformations of particle with potential implications for toxicity is so far unstudied, despite it forming a dense second layer around the strongly attached biomolecules ${ }^{24}$.

In addition to protein corona formation, ion release is central to the toxicity of silver NPs and is an important parameter studied in vitro ${ }^{25-27}$ and in vivo ${ }^{28}$. Oxidation contributes to ion release through the formation of $\mathrm{Ag}_{2} \mathrm{O}$ on the particles ${ }^{29,30}$, which is then dissolved in aqueous media ${ }^{31-33}$. Oxidative dissolution is an important step in $\mathrm{Ag}_{2} \mathrm{~S}$ formation from/at $\mathrm{Ag}$ $\mathrm{NPs}^{34}$. Silver NP sulphidation has been receiving increasing attention, as the resulting sulphide is insoluble in water, decreasing the availability of $\mathrm{Ag}^{+}$and impacting antibacterial ${ }^{35}$ and toxicological ${ }^{36-38}$ effects. After identification of silver sulphide in sewage sludge ${ }^{39}$, interest in studying $\mathrm{Ag}_{2} \mathrm{~S}$ was focused on wastewater plants ${ }^{40,41}$ and aquatic environments ${ }^{42}$. Although most toxicity experiments are conducted in vitro, much less is known about such transformations of Ag NPs under these conditions. Thiols (for example, cysteine) have been proven to bind $\mathrm{Ag}^{+}$in biological environments ${ }^{43,44}$. Tracking the oxidation state of intracellular silver showed an evolution from $\mathrm{Ag}^{0}$ to

oxygen-bound and sulphur-bound $\mathrm{Ag}$ ions ${ }^{45,46}$. Formation of $\mathrm{Ag}_{2} \mathrm{~S}$ in alveolar cells was proposed to explain decreased toxicity of silver nanowires ${ }^{47}$ and their sulphidation in protein-free culture medium was recently studied ${ }^{48}$. A further step involves exploring chemical changes that occur in full culture media, in the presence of protein coronas, before cellular uptake.

Here we demonstrate one clear role for the soft corona in modulating silver NP sulphidation in vitro, and highlight the interplay between strongly and weakly attached proteins for the chemical transformation of Ag NPs. We also suggest some potential implications for toxicity, without, however, establishing a clear direct connection between the soft corona and observed toxicological effects. We show for the first time a functional effect of rapidly exchanging proteins, which decreased the amount of nano- $\mathrm{Ag}_{2} \mathrm{~S}$ formed at polyvinylpyrrolidone (PVP)-coated Ag NPs incubated in serum-supplemented cell culture media. We propose and study a mechanism for soft corona protein-assisted $\mathrm{Ag}^{+}$ transport explaining reduced sulphide formation. Striking differences when going from in vitro to in vivo relevant protein concentrations are observed and discussed. As it is known that sulphidation decreases silver toxicity ${ }^{36-38,47,49-51}$, it is not surprising that under conditions where Ag NPs were partially or completely transformed into $\mathrm{Ag}_{2} \mathrm{~S}$ in cell culture media, much less toxicity to J774 macrophages and different cytokine secretion profiles are seen compared with silver NPs.

\section{Results}

Protein coronas modulate nano- $\mathrm{Ag}_{2} \mathrm{~S}$ formation at $\mathrm{Ag} \mathrm{NPs}$. Upon incubation of PVP-coated, cubic or quasi-spherical Ag NPs in RPMI-1640 cell culture medium supplemented with fetal bovine serum (FBS), new NPs were observed to form close to the surface of the silver. Details regarding incubation are available in the Methods section, Particle incubation in cell culture media subsection. Figure 1a shows a typical transmission electron microscopy (TEM) image of nanocubes after 7 days in $1 \%$ serum, with the NPs forming a dispersed layer around the silver core (highlighted by arrows). X-rays elemental mapping (Fig. 1b) and energy-dispersive X-ray spectroscopy (EDS, Fig. 1c) revealed the presence of sulphur. Co-localization of $\mathrm{Ag}$ and $\mathrm{S}$ matches the small NPs in the proximity of the silver surface (Fig. 1b). The
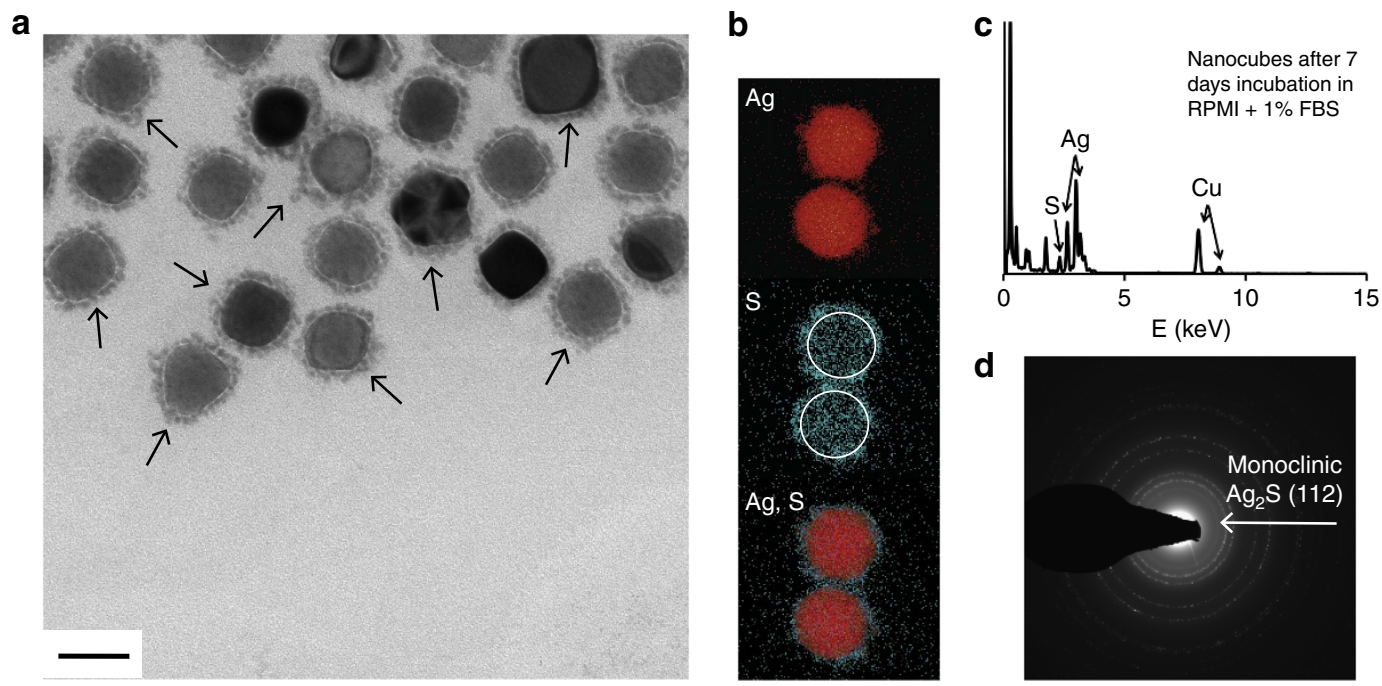

Figure 1 | Silver sulphide forms close to the surface of Ag NPs. TEM image with arrows highlighting nano- $\mathrm{Ag}_{2} \mathrm{~S}$ (a, scale bar $50 \mathrm{~nm}$ ), $\mathrm{X}$-rays elemental mapping of $\mathrm{Ag}$ (red), S (blue, with white rings marking the approximate contour of the Ag NPs) and overlaid $\mathrm{Ag}$ and $\mathrm{S}$ (b), EDS spectrum-with arrows pointing at the peaks corresponding to each element-(c) and diffraction pattern-arrow pointing at the diffraction line corresponding to monoclinic $\mathrm{Ag}_{2} \mathrm{~S}-$ (d) of silver nanocubes after 7 days incubation in RPMI-1640 supplemented with 1\% FBS and formation of $\mathrm{Ag}_{2} \mathrm{~S}$ at the surface of the $\mathrm{Ag}$ NPs. 
diffraction line at 2.80 (Fig. 1d) corresponds to monoclinic $\mathrm{Ag}_{2} \mathrm{~S}$ (ref. 52).

When in contact with biological media, NPs get covered with biomolecules ${ }^{1-4}$. Hard and soft protein coronas around silver nanocubes have previously been quantified and it has been shown that the polymer coating is replaced during the first hour in $1 \%$ serum $^{24}$. We observe no sulphide within $1 \mathrm{~h}$, before PVP replacement (Supplementary Fig. 1). The later appearance of $\mathrm{Ag}_{2} \mathrm{~S}$ close to the silver surface suggests its formation is related to the layers of adsorbed biomolecules. We hypothesize a mechanism where protein coronas and ion release govern the formation of $\mathrm{Ag}_{2} \mathrm{~S}$ at silver NPs (Fig. 2a). We propose that released $\mathrm{Ag}^{+}$can get trapped in the long-lived protein corona where, if enough reduced sulphur and $\mathrm{Ag}^{+}$are available, $\mathrm{Ag}_{2} \mathrm{~S}$ may form. In contrast, the rapidly exchanging soft corona proteins prevent sulphide formation by transporting $\mathrm{Ag}^{+}$away from the particle, thus decreasing local ion concentration. To test this hypothesis, one must account for both hard and soft corona proteins, as well as bulk biomolecules.

Silver nanocubes (Supplementary Fig. 2) were incubated in RPMI-1640 with 1\% FBS for $24 \mathrm{~h}$ (Fig. 2b) to provide a stable hard corona (Supplementary Discussion). The particles were washed, removing unbound and loosely bound proteins while retaining the hard corona (Fig. $2 c$, cartoon), and re-suspended in RPMI-1640 without serum for 6 days. Similarly, particles were incubated for 7 days in 1 or $10 \%$ FBS to ensure the presence of hard and soft coronas, and bulk proteins (Fig. 2d,e cartoon). The same behaviour was seen for quasi-spherical NPs (Supplementary Fig. 3). $\mathrm{Ag}_{2} \mathrm{~S}$ is observed under all incubation conditions where serum was present for at least the $24 \mathrm{~h}$ needed to fully form the hard corona ${ }^{24}$. Figure $2 \mathrm{c}-\mathrm{e}$ shows typical TEM images of the different conditions- 6 days at 0,1 and $10 \%$ FBS after $24 \mathrm{~h}$ in

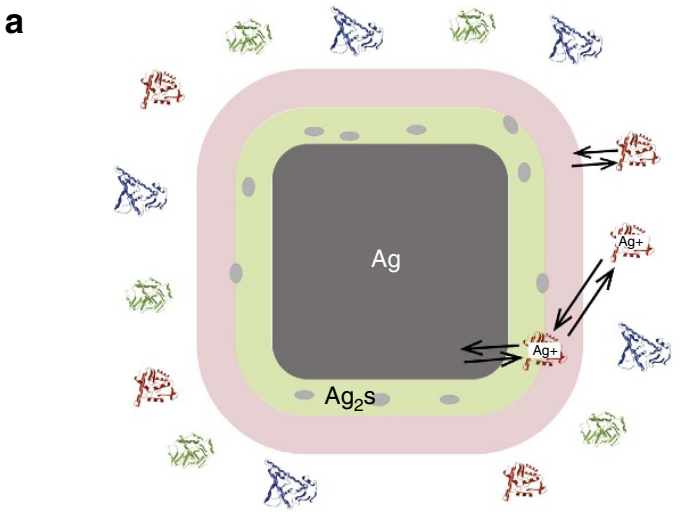

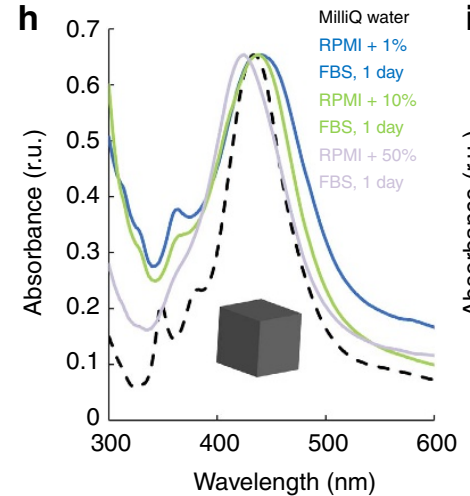
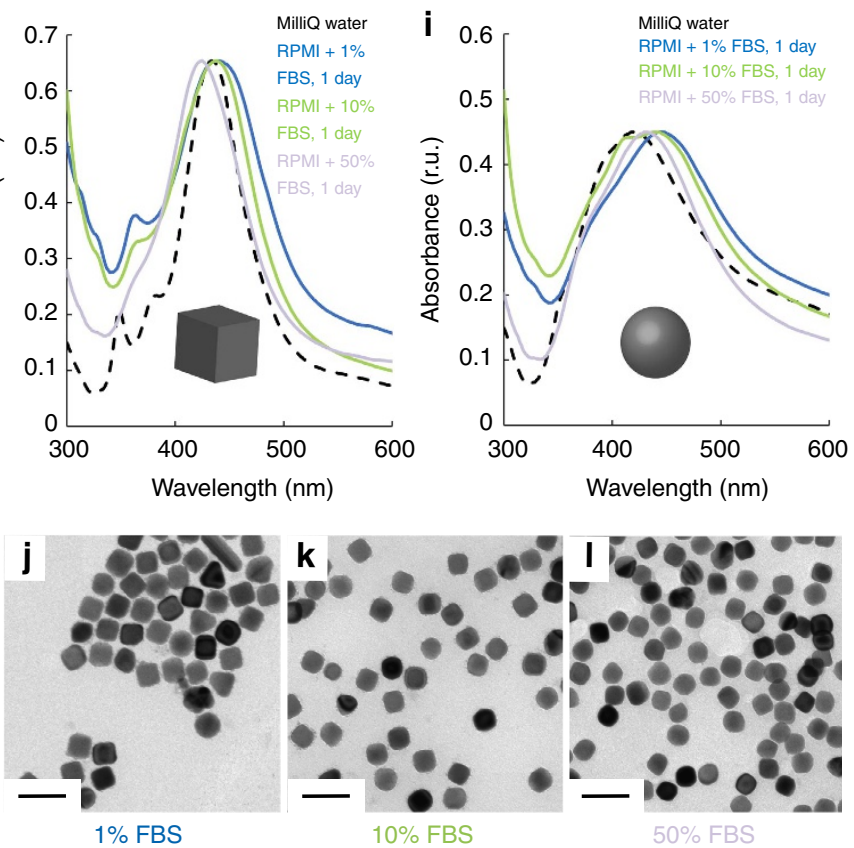

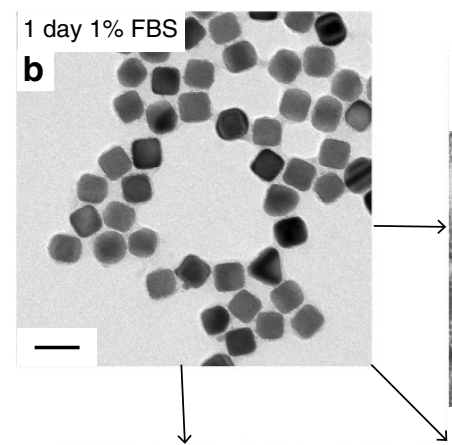

6 days $1 \%$ FBS

d
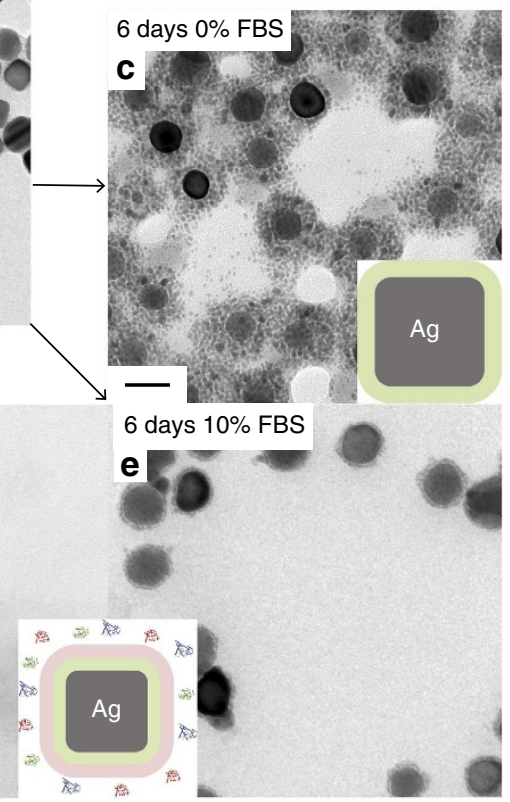

7 days $0.4 \mathrm{mg} \mathrm{ml}^{-1} \mathrm{BSA}(\approx 1 \% \mathrm{FBS}) \quad 7$ days $4 \mathrm{mg} \mathrm{ml}^{-1} \mathrm{BSA}(\approx 10 \% \mathrm{FBS})$

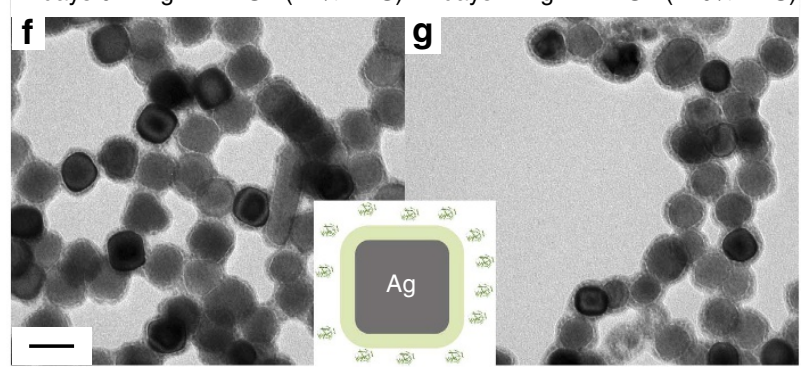

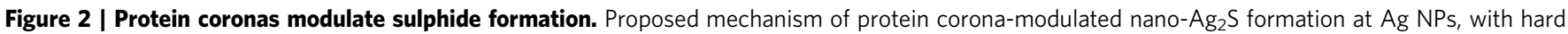
corona proteins trapping $\mathrm{Ag}^{+}$released from the nanoparticle surface and soft corona proteins transporting said ions away from the sulphide-formation centres in the long-lived corona (a); TEM images of silver nanocubes after $24 \mathrm{~h}$ in RPMI-1640 cell culture medium supplemented with $1 \%$ FBS (b), followed by 6 days incubation in RPMI-1640 with 0\% FBS (inset cartoon showing only hard corona around Ag NPs) (c), 1\% FBS (d) or 10\% FBS (e; common inset cartoon showing hard and soft coronas, as well as free bulk proteins around Ag NPs); TEM images of silver nanocubes after 7 days incubation in RPMI1640 with $0.4 \mathrm{mg} \mathrm{ml}^{-1} \mathrm{BSA}$ (f) or $4 \mathrm{mg} \mathrm{ml}^{-1} \mathrm{BSA}(\mathbf{g}$ ) (common inset cartoon showing hard corona and free bulk proteins around Ag NPs); Ultravioletvisible spectra of cubic (h) and quasi-spherical (i) Ag NPs after $24 \mathrm{~h}$ incubation in RPMI-1640 cell culture medium supplemented with 1, 10 or $50 \%$ FBS; TEM images of silver nanocubes after $24 \mathrm{~h}$ in RPMI-1640 supplemented with 1\% FBS (j), $10 \%$ FBS (k) and $50 \%$ FBS (I). Scale bars are 100 nm (b, j-I) or $50 \mathrm{~nm}(\mathbf{c}-\mathbf{g})$. 
serum-containing media. EDS confirmed the presence of sulphur (Supplementary Fig. 4). Although the total incubation time is the same (7 days) for all samples, the differences in $\mathrm{Ag}_{2} \mathrm{~S}$ amounts are striking, with significantly more sulphide observed at the particle surfaces when soft corona and free bulk proteins are absent after the first day. Incubating Ag NPs in serum-containing media for the initial $24 \mathrm{~h}$ establishes a long-lived corona, stable after the transition to $0 \%$ FBS. It has previously been shown that the hard corona is similar after $24 \mathrm{~h}$ in 1 and $10 \%$ FBS for different silver nanocubes ${ }^{24}$, and in the present study, we observed the same protein profiles for NPs of various sizes (Supplementary Fig. 5). Here there is a similar long-lived layer on all Ag NPs, as confirmed by mass spectrometry (Supplementary Tables 1-3); what varies $(0,1$ and $10 \%$ FBS $)$ are the soft corona and the bulk protein concentrations. Nano- $\mathrm{Ag}_{2} \mathrm{~S}$ formation at $\mathrm{Ag} \mathrm{NPs}$ decreased with soft corona presence and the increase in free proteins, with significantly more sulphide at $0 \%$ than $1 \%$ and $10 \%$ FBS. The variation does not appear linear: differences between 1 and $10 \%$ FBS are not as striking as between 0 and $1 \%$. Furthermore, although in the presence of serum the particles are dispersed even after 7 days (Supplementary Fig. 6), at 0\% FBS the nano- $\mathrm{Ag}_{2} \mathrm{~S}$ forms bridges between $\mathrm{Ag} \mathrm{NPs}$, which result in particle agglomeration (Fig. 2c).

Both soft corona and bulk proteins could bind $\mathrm{Ag}^{+}$; distinguishing between the two categories requires absence of one of them. To test the role of soft coronas, bovine serum albumin (BSA), at concentrations equivalent to 1,10 or $50 \%$ FBS, was used to form a hard corona around silver nanocubes (Supplementary Fig. 7). When only BSA is present in the system, the protein-protein interactions needed to form soft coronas do not occur (Supplementary Fig. 8 and Supplementary Methods); incubation in albumin provides only hard coronas and bulk proteins (Fig. 2f,g, cartoon). Figure 2f,g shows slightly more nano- $\mathrm{Ag}_{2} \mathrm{~S}$ formation when BSA concentration is increased from equivalent of $1 \% \mathrm{FBS}$ to $10 \% \mathrm{FBS}$; the opposite phenomenon is observed for serum (Fig. 2d,e). Full sets of TEM images are available (Supplementary Figs 9 and 10); similar results were obtained when using lysozyme instead of BSA (Supplementary Figs 11 and 12). The observed increase in $\mathrm{Ag}_{2} \mathrm{~S}$ content at higher albumin/lysozyme concentrations may be due to a thicker, fasterformed hard corona, allowing for trapping and sulphidation of more $\mathrm{Ag}^{+}$. Although sulphide appears for incubation in both FBS and BSA/lysozyme, increasing serum concentration-unlike increasing albumin/lysozyme concentration-decreases $\mathrm{Ag}_{2} \mathrm{~S}$ formation. This is attributed to the lack of a soft corona when a single type of protein exists in the system ${ }^{11}$-as shown in Supplementary Fig. 8 and Supplementary Methods-as hard coronas and free bulk proteins are present in both cases.

To further study the soft corona influence, experiments were performed at serum concentrations from 1 to $50 \%$, over $24 \mathrm{~h}$. Ultraviolet-visible spectra were collected and plasmon peak shifts were observed. Owing to localized surface plasmon resonances, variations in peak position indicate refractive index changes around particles. Red shifts of 2-4 nm upon binding of proteins to Ag NPs have been seen previously ${ }^{24}$. Here, we observe changes of up to $45 \mathrm{~nm}$ indicating the presence of a material with high refractive index-like $\mathrm{Ag}_{2} \mathrm{~S}$-close to the $\mathrm{Ag}$ NPs. Comparison to TEM images (Fig. 2j,l and Supplementary Figs 13 and 14) shows the more sulphide present at the surface, the larger the red-shift in the plasmon peaks is. Increased protein concentration and, therefore, soft corona protein content ${ }^{24}$, results in a visible decrease of nano- $\mathrm{Ag}_{2} \mathrm{~S}$ formation not just at prolonged incubation, but also after $24 \mathrm{~h}$. Analysis of multiple TEM images revealed almost no sulphide at the NP surface in $50 \%$ serum. Furthermore, TEM and ultraviolet-visible data indicate a lower sulphide content after $24 \mathrm{~h}$ in $10 \%$ compared with $1 \%$ FBS.
Figure 2h,i shows spectra for cubic and quasi-spherical Ag NPs after $24 \mathrm{~h}$ in 1,10 or $50 \%$ serum. Decreasing FBS concentration and, implicitly, the amount of soft corona ${ }^{24}$, results in the formation of more $\mathrm{Ag}_{2} \mathrm{~S}$ at $\mathrm{Ag}$ NPs, as suggested by the plasmon peak shifted towards higher wavelengths when going from $50 \%$ to $10 \%$ and $1 \%$ serum. NP dissolution (Supplementary Fig. 15) results in reshaping and resizing on a similar timescale for these nanocubes, with concomitant changes of the optical spectra. This leads to the decreased intensity of the signal around $350 \mathrm{~nm}$, where a more prominent peak is characteristic of larger silver nanocubes, with sharper edges ${ }^{53}$. Reduction in particle diameter, coupled with shape changes from cubes to sphere-like, also explains the blue-shift around $435 \mathrm{~nm}$ (Fig. 2h) after incubation in 50\% serum. No reshaping is observed for the quasi-spherical NPs, while slight diameter decrease may occur.

It has been shown that shifts in plasmon peak position, coupled with finite-difference time-domain simulations of plasmonic behaviour may be used to quantify refractive index changes caused by protein adsorption at $\mathrm{Ag} \mathrm{NPs}^{24}$. Via a similar approach (Supplementary Figs 16 and 17, Supplementary Table 4 and Supplementary Methods) we estimate that, at the Ag NP concentration used here $\left(10 \mu \mathrm{g} \mathrm{ml}^{-1}\right), 15-40 \%$ of the silver is transformed into sulphide.

Ion release from $\mathrm{Ag} \mathrm{NPs}$ is necessary for nano- $\mathrm{Ag}_{2} \mathrm{~S}$ formation. Sulphidation of silver NPs involves the presence of ionic silver therefore variations in $\mathrm{Ag}^{+}$content may influence the formation of $\mathrm{Ag}_{2} \mathrm{~S}$. To test this parameter, $\mathrm{AgNO}_{3}$-with $\mathrm{Ag}^{+}$representing $10 \%$ by weight of the particulate silver-was added to the NP suspension at the beginning of 1 or 7 days incubation in RPMI1640 with 1\% FBS (Supplementary Figs 18-21 for 10\% serum). ultraviolet-visible spectra of quasi-spherical particles with or without extra ions were collected (Fig. 3a); a less pronounced redshift was seen when free $\mathrm{Ag}^{+}$were added, especially at short incubation, suggesting a slower NP dissolution in the presence of extra ions.

Nanocubes have several characteristic plasmon peaks, of which a quadrupole $(\approx 350 \mathrm{~nm})$ and a dipole $(\approx 435 \mathrm{~nm}$; Supplementary Fig. 18). The quadrupole indicates the degree to which a NP is cubic, as well as its size ${ }^{53}$, and, as such, it is used to track the synthesis of silver nanocubes ${ }^{54}$ (Supplementary Fig. 22). Dissolution reduces particle size and blunts cube edges, resulting in flattening of the quadrupole peak (Fig. 3b). After 7 days in $1 \%$ FBS, the signal disappears almost completely.. At $24 \mathrm{~h}$, both samples exhibit a pronounced quadrupole peak, with a visibly sharper signal when $10 \%$ free $\mathrm{Ag}^{+}$were added at the beginning of the incubation. The results suggest Ag NPs in samples with added ions undergo slower and, perhaps, less dissolution, observable in resizing and reshaping of the particles. This behaviour could be explained by the existence of a plateau ion concentration in the bulk, as previously observed ${ }^{32,45}$. Adding free ions may decreases the amount of $\mathrm{Ag}^{+}$required from NP dissolution for achieving this equilibrium concentration, but further investigations would be necessary to elucidate the mechanism.

Inspection of multiple TEM images suggests there is no difference in the amount of $\mathrm{Ag}_{2} \mathrm{~S}$ at silver NPs with or without added $10 \% \mathrm{Ag}^{+}$at 7 days, but some decrease in sulphide incidence occurs at $24 \mathrm{~h}$ (Supplementary Fig. 19). This indicates the formation of nano- $\mathrm{Ag}_{2} \mathrm{~S}$ requires the release of $\mathrm{Ag}^{+}$from NPs and not just the existence of free ions in the bulk. The observation is strengthened by control experiments with silica particles in RPMI-1640 with FBS and free silver ions; no nano$\mathrm{Ag}_{2} \mathrm{~S}$ was detected after 7 days (Supplementary Fig. 23). 

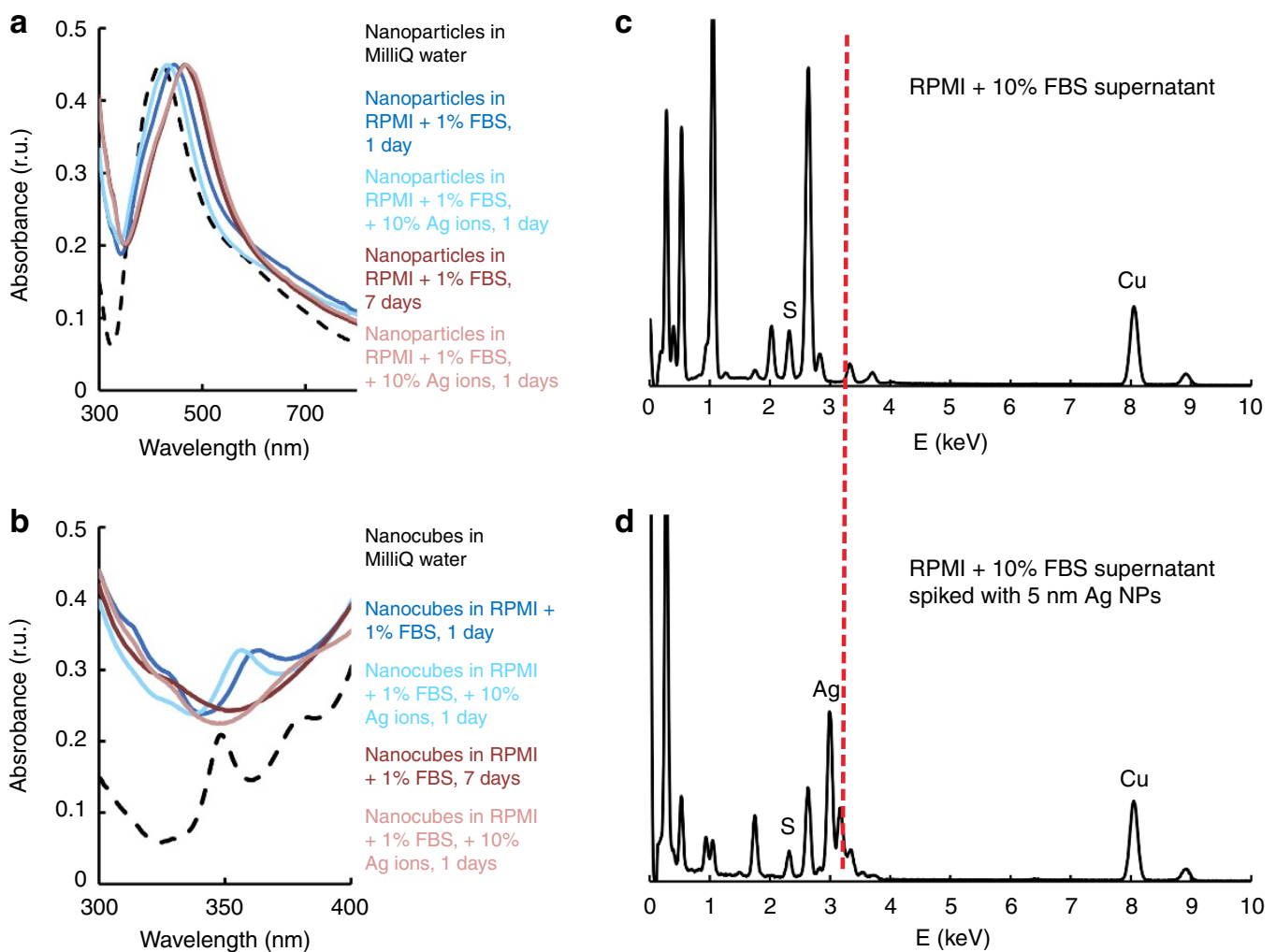

Figure 3 | Silver nanoparticle dissolution is involved in nano- $\mathbf{A g}_{2} \mathbf{S}$ formation. Ultraviolet-visible full spectra of quasi-spherical Ag NPs (a) and quadrupole peak detail of nanocubes (b) incubated (1 day: blue or 7 days: pink) in RPMI-1640 cell culture medium supplemented with 1\% FBS, with or without added extra $10 \%$ (by mass) $\mathrm{Ag}^{+}$ions from $\mathrm{AgNO}_{3}$; $\mathrm{EDS}$ spectra of the supernatant obtained after centrifugation of $\mathrm{Ag}$ NPs incubated for 7 days in RPMI-1640 with $1 \%$ FBS, before (c) and after (d) spiking with $5 \mathrm{~nm}$ PVP-coated Ag NPs, with dotted red line highlighting the presence of a silver signal only in the spiked sample.

Atomic absorption spectroscopy (Supplementary Fig. 15) confirmed the presence of silver in the bulk, strengthening the soft corona ion transport mechanism; it did not, however, indicate the chemical form of the silver. Although the timescale of soft corona exchange is on the order of seconds and minutes and nano- $\mathrm{Ag}_{2} \mathrm{~S}$ formation occurs over hours, we verified that at prolonged incubation the rapidly exchanging proteins do not transport $\mathrm{Ag}_{2} \mathrm{~S}$ nano-crystals away from the $\mathrm{Ag} \mathrm{NP}$ surface. We measured EDS spectra and mapped supernatants collected after 7 days incubation in $1 \%$ FBS, before and after spiking in PVP-coated Ag NPs (Fig. 3c,d and Supplementary Fig. 24) of similar size $(5 \mathrm{~nm})$ and amount to that of nano- $\mathrm{Ag}_{2} \mathrm{~S}$. If $\mathrm{Ag}_{2} \mathrm{~S}$ nanocrystals were transported to the bulk, a peak would appear in the EDS spectrum around $3 \mathrm{keV}$. Absence of this signal in the unspiked supernatant indicates nano- $\mathrm{Ag}_{2} \mathrm{~S}$ is not transported by the soft corona.

Sulphur sources and $\mathrm{Ag} / \mathrm{S}$ ratio influence nano- $\mathrm{Ag}_{2} \mathrm{~S}$ formation. Sulphur-containing gases can contribute to the formation of $\mathrm{Ag}_{2} \mathrm{~S}$ at $\mathrm{Ag}$ NPs exposed to air, but this is a lengthy and slow process, extended over 24 weeks ${ }^{55}$. In the liquid phase, RPMI1640 provides several sulphur sources (Supplementary Tables 5 and 6), with L-cysteine and L-methionine accounting for most of the reduced $S$; furthermore, many serum proteins contain cysteine residues. To pin-point the sulphur responsible for $\mathrm{Ag}_{2} \mathrm{~S}$ formation in our case, we incubated Ag NPs in phosphatebuffered saline (PBS) supplemented with either 1\% FBS or L-cysteine and L-methionine at the same concentrations as in RPMI-1640. After 7 days, no sulphide was seen in PBS or in buffer with serum (Fig. 4a,b), but nano- $\mathrm{Ag}_{2} \mathrm{~S}$ was present in the amino-acid-supplemented buffer (Fig. 4c and Supplementary Fig. 25). EDS spectra (Fig. 4d) confirmed the observations from TEM images. These experiments show reduced sulphur from small molecules and not from proteins is the one forming $\mathrm{Ag}_{2} \mathrm{~S}$.

We further tested the effect of $\mathrm{Ag} / \mathrm{S}$ ratios by varying the amount of nanocube stock suspension added to a given volume of serum-supplemented RPMI-1640. After 7 days, increasing the initial silver concentration from 2 to 10 and then to $100 \mu \mathrm{g} \mathrm{ml}^{-1}$ (Fig. 4e-g and Supplementary Fig. 26) drastically decreases $\mathrm{Ag}_{2} \mathrm{~S}$ formation by limiting the L-cysteine and L-methionine available per $\mathrm{Ag}^{+}$. In vivo cysteine concentration is more than double that in RPMI, making more $\mathrm{S}$ available for $\mathrm{Ag}_{2} \mathrm{~S}$ formation ${ }^{56,57}$. At the lowest $\mathrm{Ag} / \mathrm{S}$ ratio, the particles are almost entirely transformed into $\mathrm{Ag}_{2} \mathrm{~S}$, forming 'pockets' of sulphide that conserve the shape of the initial particle, with the metal core still visible in some cases (Fig. 4e). These observations suggest sulphidation is confined to the protein hard corona, in agreement with EDS showing the absence of nano- $\mathrm{Ag}_{2} \mathrm{~S}$ from the suspension supernatant (Fig. 3c,d).

Protein corona-mediated sulphidation impacts cell toxicity. Previous research has already shown that trapping $\mathrm{Ag}^{+}$in the form of insoluble $\mathrm{Ag}_{2} \mathrm{~S}$ decreases the toxicity of silver $\mathrm{r}^{50,51}$ and $\mathrm{Ag}$ $\mathrm{NPs}^{35,49}$, mostly in the case of aquatic environments ${ }^{36,37,58}$ and in soil ${ }^{38}$, which are settings with low protein contents, but higher concentrations of other components that are not prevalent under in vitro cell study conditions. Although the effects under in vitro parameters have not been studied to the same extent, some information is also available on the decreased toxicity of sulphidated Ag NPs to cultured cells ${ }^{47}$. Our results confirm 

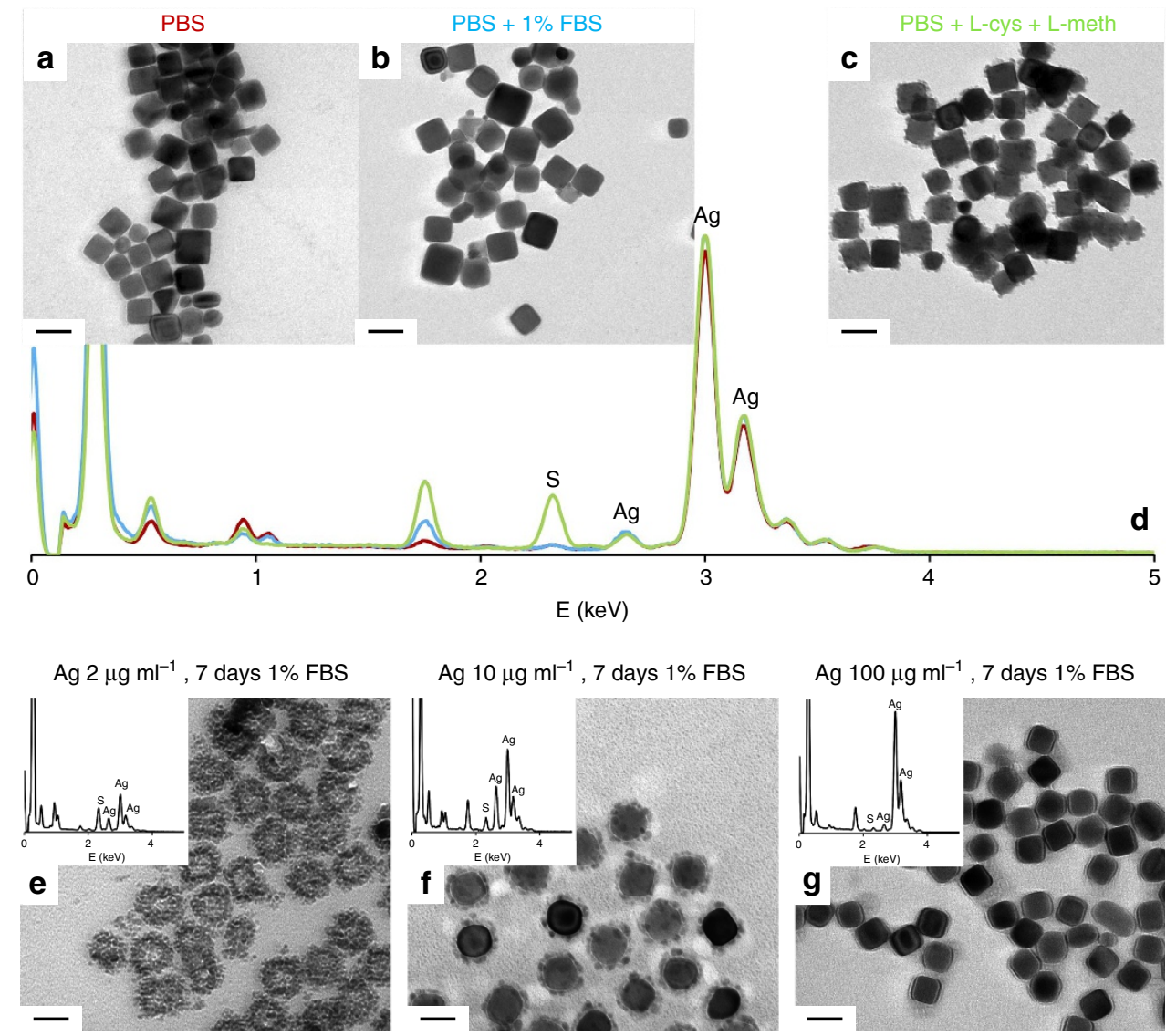

Figure 4 | Sulphur sources and the Ag:S ratio influence $\mathbf{A g}_{\mathbf{2}} \mathbf{S}$ formation. TEM images of $\mathrm{Ag}$ NPs after 7 days incubation in PBS (a), PBS supplemented with $1 \%$ FBS (b) and PBS supplemented with L-cysteine and L-methionine at the same concentrations of amino acids as those found in RPMI-1640 (c) and corresponding EDS spectra (d); TEM images and corresponding EDS spectra (insets) of Ag NPs after 7 days incubation in RPMI-1640 supplemented with $1 \% \mathrm{FBS}$, with initial silver concentrations of $2 \mu \mathrm{g} \mathrm{ml}^{-1}$ (e), $10 \mu \mathrm{g} \mathrm{ml}^{-1}$ (f) and $100 \mu \mathrm{g} \mathrm{ml}^{-1}$ (g), with elemental mapping images provided in Supplementary Fig. 26. Scale bars are $100 \mathrm{~nm}(\mathbf{a}-\mathbf{c})$ or $50 \mathrm{~nm}(\mathbf{e}-\mathbf{g})$.

such already published findings and extend the observations to a cell line where the consequences of sulphidation have not previously been investigated. We indirectly tested the effects of corona-mediated sulphidation on the toxicity of Ag NPs to J774 macrophages by exposing cells to partially and completely sulphidated NPs (obtained by pre-incubation in 10 and $1 \%$ FBS respectively, Fig. 5a,b) to mimic in vitro conditions, as well as NPs with no sulphide, to mimic in vivo settings (Supplementary Fig. 27). Detailed experimental procedures are available in the Methods section and in Supplementary Methods. Ag NPs disrupted mitochondrial activity, as measured using a 3-(4,5dimethylthiazol-2-yl)-2,5-diphenyltetrazolium bromide (MTT) assay, and caused cell death at concentrations above $25 \mathrm{\mu g} \mathrm{ml}^{-1}$, whereas partially and completely transformed particles showed no effect at concentrations as high as $100 \mu \mathrm{g} \mathrm{ml}^{-1}$ (Fig. 5c). Silver ions were lethal to the cells even at the lowest concentration $\left(2 \mu \mathrm{g} \mathrm{ml}^{-1}\right)$, but pristine, partially and completely sulphidated Ag NPs were suitable for analysis of potential effects at sub-lethal doses. Of all the molecules measured in the cell supernatants, responses above the detection limit were seen for interleukin-1beta, interleukin-6, interleukin-18, tumour necrosis factor alpha (TNF $\alpha$ ) and macrophage inflammatory protein 2 (MIP-2; Supplementary Fig. 28 and Fig. 5). Granulocyte-macrophage colony-stimulating factor was also measured at the highest particle doses in the Ag NPs samples, but for most systems, granulocyte-macrophage colony- stimulating factor values were below the detection limit and, therefore, they are not included here. The most pronounced impact is observed on TNF $\alpha$ and MIP-2. TNF $\alpha$ is a cytokine released by macrophages at early inflammatory stages together with interleukin 6 (ref. 59), which we also observed (Supplementary Fig. 28). A threefold increase in its production is caused by pristine and partially sulphidated Ag NPs, but not by completely transformed ones (Fig. 5d). This result indicates upregulation of TNF $\alpha$ production by Ag requires the presence of nano-particulate or ionic silver, as previously seen ${ }^{60,61}$. A similar trend (Fig. 5e) was observed for MIP-2, a cytokine involved in cell recruitment to the site of infection following the initiation of the inflammatory response ${ }^{62}$. Together, these results confirm that sulphidation, which we show is mediated by the dynamic protein coronas and is more likely to occur at the serum concentrations used in vitro than in vivo, decreases the toxicity of silver NPs both at lethal and sub-lethal doses. However, although we show, for the first time, a link between both soft and hard protein coronas and Ag NPs sulphidation and confirm previous findings connecting sulphidation to decreased toxicity, we cannot, at this time, provide a direct link between the soft corona and the diminished toxicological effects of sulphidated Ag NPs. Furthermore, technical limitations in conducting in vitro studies at different FBS concentrations do not allow us to account for the $\mathrm{Ag}^{+}$transported by soft corona proteins in the bulk of the pre-incubation system. As silver ions are known for their toxicity 

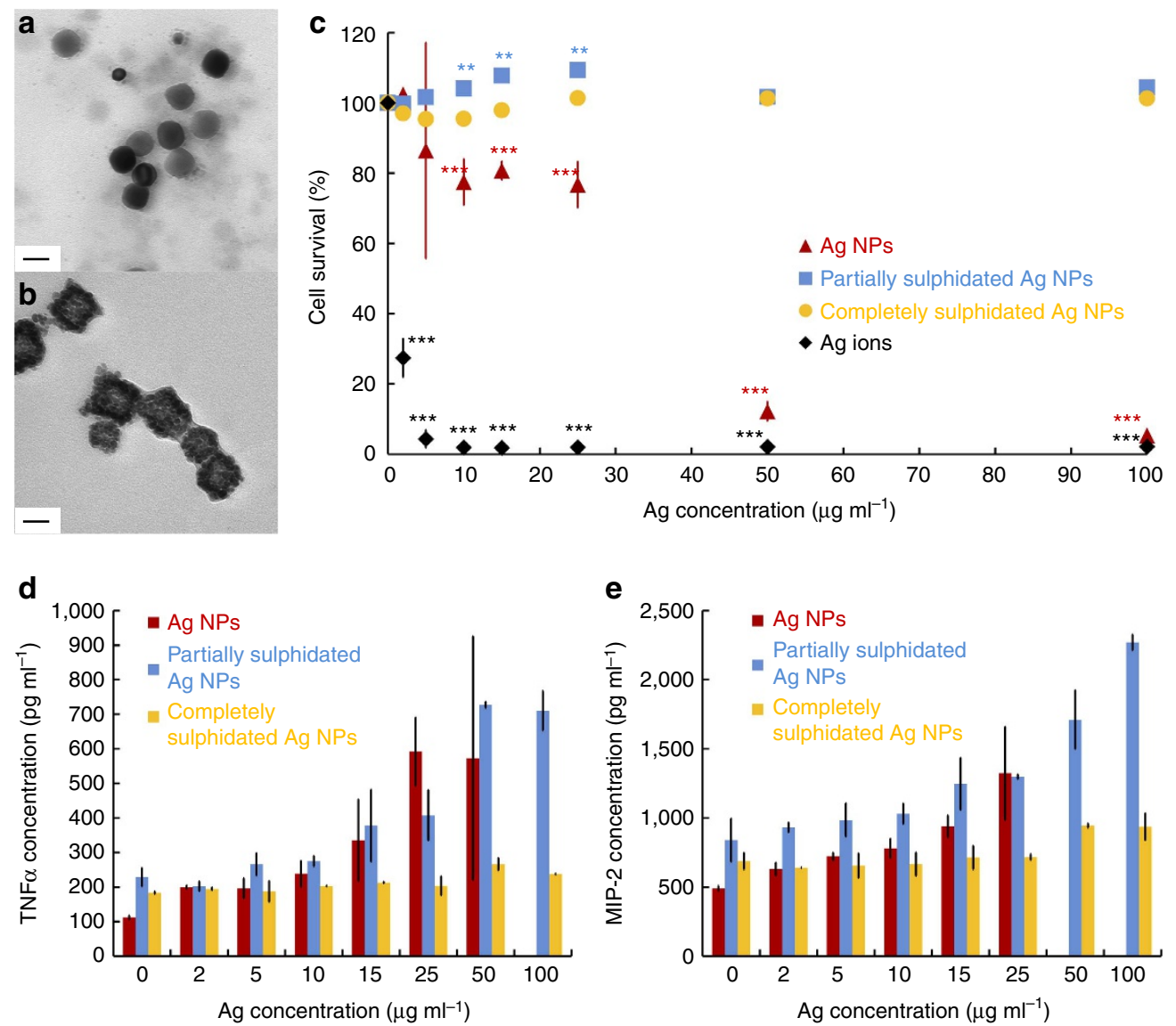

Figure 5 | Corona-mediated sulphidation of Ag NPs impacts particle toxicity. TEM images of partially sulphidated Ag NPs after pre-incubation in RPMI1640 with 10\% FBS (a) and completely sulphidated Ag NPs after pre-incubation in RPMI-1640 with 1\% FBS (b); scale bars are $50 \mathrm{~nm}$; Viability of J774 murine macrophages (as measured with MTT assays) after $24 \mathrm{~h}$ exposure to various concentrations $\left(2,5,10,15,25,50\right.$ and $\left.100 \mu \mathrm{g} \mathrm{ml}{ }^{-1}\right)$ of $\mathrm{Ag}^{+}$ions (black diamonds), pristine Ag NPs (red triangles), partially sulphidated Ag NPs (blue squares) and completely sulphidated Ag NPs (orange circles); error bars are provided as standard deviation; statistically significant differences (two-tailed t-test, with all data sets showing normal distribution and similar variance values) as compared with the control are marked with ${ }^{\star \star} P<0.005$ or ${ }^{\star \star \star} P<0.0005(n=6)$, with all the $P$ values available in Supplementary Table 7 (c); release profiles of TNF $\alpha$ (d) and MIP-2 (e) after $24 \mathrm{~h}$ exposure of $\mathrm{J774}$ macrophages to various concentrations (2, 5, 10, 15, 25, 50 and $100 \mu \mathrm{g} \mathrm{ml}^{-1}$ ) of pristine (red), partially sulphidated (blue) and completely sulphidated (orange) Ag NPs; the missing concentrations of TNF $\alpha$ and MIP-2 after exposure to pristine Ag NPs are above the measuring limit (see calibration curves in Supplementary Fig. 29).

and our experimental setting does not permit investigation of their interaction with cells when bound to rapidly exchanging proteins, we cannot make a general claim about the overall toxicological impact that the soft corona-mediated biotransformation of $\mathrm{Ag} \mathrm{NPs}$ has under various in vitro or in vivo scenarios.

\section{Discussion}

We have shown for the first time a situation where the weakly attached protein layer forming the soft corona has a visible and measurable effect on the transformation of Ag NPs in a complex biological environment. We demonstrated the presence of crystalline nano- $\mathrm{Ag}_{2} \mathrm{~S}$ at the surface of silver NPs upon incubation in cell culture medium. Reduced sulphur, an organic layer at the Ag NPs and release of ions from the metal core are necessary for sulphide formation. Protein concentration greatly impacted the amount of nano- $\mathrm{Ag}_{2} \mathrm{~S}$ observed at the particles through a soft corona protein-assisted mechanism of $\mathrm{Ag}^{+}$removal. In the absence of a rapidly exchanging corona, the decrease in sulphide formation upon increased bulk protein concentration was no longer observed, in agreement with the proposed mechanism. Greater free silver ion concentrations introduced in the media did not increase sulphide formation. We have studied well-defined Ag nanocubes and quasi-spherical particles formed via PVP stabilization. Although we expect the proposed mechanism to apply to Ag NPs having other sizes, shapes and coatings, the particulars of the experimental situation-such as incubation time, media, $\mathrm{Ag}_{2} \mathrm{~S}$ formation rate and crystal size, protein concentration-are likely to influence the specific outcomes.

The low water solubility of $\mathrm{Ag}_{2} \mathrm{~S}$ decreases $\mathrm{Ag}^{+}$ions bioavailability and, although this phenomenon has been studied extensively in ecotoxicology settings ${ }^{32,37,39-42}$, little is known about the effect of NP sulphidation in cell culture media ${ }^{48}$. Ions are an important component in silver toxicity to cells; transformations impacting their availability should be taken into account when analysing the stability of Ag NPs in proteincontaining media relevant for in vitro experiments and interpreting subsequent toxicity studies. We show that even partial sulphidation of Ag NPs prevents cell death, whereas complete sulphidation also prevents the increased pro-inflammatory cytokines production seen with pristine particles. The observed decrease in $\mathrm{Ag}_{2} \mathrm{~S}$ formation at increased protein contents may raise a question regarding using in vitro results to predict in vivo scenarios, as the bulk biomolecule 
concentration in the latter settings is much higher than in the former. However, for this to become an issue, a direct link between the dynamic protein coronas and the toxic effects of $\mathrm{Ag}$ NPs should first be established in future research. Further studies into the bioavailability and effects of soft corona-bound $\mathrm{Ag}^{+}$from particle dissolution in protein-containing media are also necessary to obtain a clear and full picture of how biomolecules-modulated biotransformations may change NPs' toxicity effects in vitro and in vivo.

\section{Methods}

Particle synthesis and characterization. Silver NPs, both cubic and quasispherical, were prepared using the polyol method ${ }^{63}$, where particle shape is controlled by the ratio between the capping agent (PVP) and the silver precursor ${ }^{64}$. Briefly, a specific amount of silver trifluoroacetate dissolved in anhydrous ethylene glycol is reduced by ethylene glycol at high temperature $\left(145-155^{\circ} \mathrm{C}\right)$ in the presence of PVP $(\mathrm{Mw} \approx 55,000 \mathrm{Da})$. The ratio of PVP to $\mathrm{CF}_{3} \mathrm{COOAg}$ dictates the outcome regarding particle shape. For the cube synthesis, trace amounts of $\mathrm{HCl}$ and $\mathrm{NaSH} \cdot \mathrm{xH}_{2} \mathrm{O}$ are added to the reaction mixture, as described elsewhere ${ }^{63}$. The particles were purified by repeated washing with acetone, ethanol and MilliQ water ${ }^{24}$. The synthesis was tracked by collecting ultraviolet-visible spectra (Shimadzu UV-visible-NIR spectrophotometer, UV-3600) of the reaction mixture (a few drops in MilliQ water) at various times (Supplementary Fig. 22). The resulting silver particles were quantified using flame atomic absorption spectroscopy (F-AAS, PerkinElmer Analyst 300 atomic absorption spectrometer mounted with a silver lumina hollow cathode lamp), after digestion in $65 \% \mathrm{HNO}_{3}$. NP size was obtained using the SPIP scanning probe image software (Image Metrology) to analyse TEM images of at least 500 particles.

Particle incubation in cell culture media. RPMI-1640 (Invitrogen) is a medium widely used for cell cultures, including for the J774 murine macrophages employed here. We incubated Ag NPs (cubic or quasi-spherical) in RPMI-1640 with or without added supplements of heat-inactivated FBS (HyClone; $1-50 \%$ by volume), for 1 or 7 days. As we are studying a model system from the perspective of a mechanism of chemical transformation, our choice of serum concentrations and incubation times is only partially based on real toxicology settings. As such, $10 \%$ FBS is used as the typical serum supplement for in vitro toxicity studies ${ }^{65-67}$, with $24 \mathrm{~h}$ being the go-to time for acute toxicity experiments ${ }^{26,45,65-69}$. However, in vitro Ag NPs exposure studies have been performed at lower serum concentrations ${ }^{45,68,69}$, down to $1 \%$ (ref. 25), which is the concentration selected in our work. Furthermore, the $1 \%$ provides a better model system to study and understand mechanisms, as the low protein concentration makes the protein exchange-dependant process at the NP surface take longer, with fewer biomolecules available to participate. Although FBS contents higher than $10 \%$ are not common for in vitro studies, they are closer to an in vivo situation, so $50 \%$ serum was selected to better investigate the behaviour of $\mathrm{Ag}$ NPs in a realistic setting. However, we perform a mechanistic study on model systems, therefore the incubation times were chosen to have a fully formed hard corona on $\mathrm{Ag} \mathrm{NPs}^{24}(24 \mathrm{~h})$ and to observe an extensive chemical transformation of the NPs (7 days), even though the onset of the sulphidation occurs, as we show, much earlier and clear changes are visible at $24 \mathrm{~h}$. To study the influence of free ions on nano- $\mathrm{Ag}_{2} \mathrm{~S}$ formation, $\mathrm{AgNO}_{3}$ (Sigma-Aldrich) aqueous solutions $\left(10 \% \mathrm{Ag}^{+}\right.$by weight of the total Ag NP mass) were added to the media at the beginning of the incubation process for some of the samples.

Sample analysis post-incubation. Ultraviolet-visible spectra were collected against a MilliQ water background, over a wavelength domain of $300-800 \mathrm{~nm}$. The peak positions of the resulting spectra were assessed using the Savitzky-Golay method to derive the spectral plots in the SpecManager software (ACD Labs). After incubation, free proteins were eliminated by centrifugation of particles in a Heraeus Multifuge X1R table top centrifuge (Thermo Scientific) and removal of the supernatant. The silver ions in the supernatants were quantified through F-AAS. Ag NPs were washed with MilliQ water three times through re-dispersion of the pellets and TEM/STEM samples were prepared by dropping 5-10 $\mu$ l of suspension on a formvar/carbon-supported copper grid (Ted Pella) and leaving it to dry overnight. Imaging and diffraction studies were performed using a Phillips CM20 transmission electron microscope working at $200 \mathrm{keV}$. EDS and X-ray elemental mapping experiments were performed on a Talos 200X STEM instrument.

EDS and elemental mapping of supernatants. Silver nanocubes were incubated $\left(10 \mu \mathrm{g} \mathrm{ml}^{-1}\right)$ for 7 days in RPMI-1640 cell culture medium supplemented with $1 \%$ FBS. The resulting sample was centrifuged to pellet the particles. A drop of the supernatant was deposited on a formvar/carbon-supported TEM copper grid and left to dry overnight. $150 \mu$ l of the remaining supernatant was separated from the pelleted particles, moved to a clean Eppendorf tube and spiked with $40 \mu \mathrm{l}$ of PVP-coated NanoXact $5 \mathrm{~nm}$ Ag NPs (nanoComposixm, stock concentration $20 \mu \mathrm{g} \mathrm{ml}^{-1}$ ). The NanoXact Ag NPs used for spiking are comparable in size to the observed $\mathrm{Ag}_{2} \mathrm{~S}$ nanocrystals and the amount added provides a mass of silver comparable to that in the $\mathrm{Ag}_{2} \mathrm{~S}$ nanocrystals formed at the Ag NPs. A drop of the spiked supernatant was deposited on a TEM grid and left to dry overnight. EDS spectra and elemental maps from the resulting samples were collected using a Talos 200X STEM machine.

Cell line. The J774A.1 murine macrophage cell line (referred to as J774) was obtained from Cell Line Service (\#400220). The cells were cultured in RPMI-1640 cell culture medium supplemented with penicillin $\left(100 \mu \mathrm{g} \mathrm{ml}^{-1}\right)$, streptomycin $\left(100 \mathrm{U} \mathrm{ml}^{-1}\right)$, GlutaMAX $(1 \times)$ and $10 \%$ heat-inactivated FBS. The cells were kept in at $37^{\circ} \mathrm{C}$ humidified atmosphere with $5 \% \mathrm{CO}_{2}$. The cell culture medium and all the supplements were purchased from Gibco.

Particle pre-incubation and toxicity studies. Pristine Ag nanocubes, as well as partially and completely sulphidated Ag nanocubes were used for toxicity testing Silver NPs $\left(2 \mu \mathrm{g} \mathrm{ml}^{-1}\right)$ were pre-incubated in RPMI-1640 supplemented with 10 or $1 \%$ FBS, resulting in either their partial or their complete transformation into $\mathrm{Ag}_{2} \mathrm{~S}$ (Supplementary Fig. 27). After pre-incubation, the samples were centrifuged the supernatants were removed and the pelleted particles were re-suspended in RPMI-1640 with $10 \%$ FBS. Re-suspension was done in such a way as to upconcentrate the samples to the desired concentrations, namely $2,5,10,15,25,50$ and $100 \mu \mathrm{g} \mathrm{ml}^{-1}$ silver. For each of the final concentrations, pre-incubation was done in separate tubes. For the partially and completely transformed Ag NPs, up-concentration was done correcting for the amount of silver lost through ion release during pre-incubation. The resulting samples were fed to the J774 cells. Dosing of the cells was performed in a blinded experimental setting with the researcher performing the toxicity studies not being informed of the specific content of each tube provided for cell treatment. Cytokine production was quantified using a multiplex assay and cell mitochondrial activity was measured using an MTT assay (Supplementary Methods) in six separate replicates. Sample sizes down to three are routinely used in MTT assays. We believe larger sample numbers (six in this case) only serve to strengthen the significance of the results. Values are calculated as mean \pm standard deviation.

Data availability. The authors declare that the data supporting the findings of this study are available within the article and its supplementary information files.

\section{References}

1. Monopoli, M. P., Åberg, C., Salvati, A. \& Dawson, K. A. Biomolecular coronas provide the biological identity of nanosized materials. Nat. Nanotechnol 7, 779-786 (2012).

2. Walczyk, D., Baldelli Bombelli, F., Monopoli, M. P., Lynch, I. \& Dawson, K. A. What the cell "sees" in bionanoscience. J. Am. Chem. Soc. 132, 5761-5768 (2010)

3. Tenzer, S. et al. Rapid formation of plasma protein corona critically affects nanoparticle pathophysiology. Nat. Nanotechnol 8, 772-781 (2013).

4. Walkey, C. D. et al. Protein corona fingerprinting predicts the cellular interaction of gold and silver nanoparticles. ACS Nano 8, 2439-2455 (2014).

5. Albanese, A. et al. Secreted biomolecules alter the biological identity and cellular interactions of nanoparticles. ACS Nano 8, 5515-5526 (2014).

6. Walkey, C. D., Olsen, J. B., Guo, H., Emili, A. \& Chan, W. C. W. Nanoparticle size and surface chemistry determine serum protein adsorption and macrophage uptake. J. Am. Chem. Soc. 134, 2139-2147 (2012).

7. Pelaz, B. et al. Interfacing engineered nanoparticles with biological systems: anticipating adverse nano-bio interactions. Small 9, 1573-1584 (2013).

8. Docter, D. et al. The nanoparticles biomolecule corona: lessons learned - challenge accepted? Chem. Soc. Rev. 44, 6094-6121 (2015)

9. Del Pino, P. et al. Protein corona formation around nanoparticles - from the past to the future. Mater. Horiz 1, 301-313 (2014)

10. Casals, E., Pfaller, T., Duschl, A., Oostingh, G. J. \& Puntes, V. Time evolution of the nanoparticle protein corona. ACS Nano 4, 3623-3632 (2010).

11. Röcker, C., Pötzl, M., Zhang, F., Parak, W. J. \& Nienhaus, G. U. A quantitative fluorescence study of protein monolayer formation on colloidal nanoparticles. Nat. Nanotechnol 4, 577-580 (2009).

12. Milani, S., Baldelli Bombelli, F., Pitek, A. S., Dawson, K. A. \& Rädler, J. Reversible versus irreversible binding of transferrin to polystyrene nanoparticles: soft and hard corona. ACS Nano 6, 2533-2541 (2012).

13. Monopoli, M. P. et al. Physical-chemical aspects of protein corona: relevance to in vitro and in vivo biological impacts of nanomaterials. J. Am. Chem. Soc. 133, 2525-2534 (2011).

14. Fedeli, C. et al. The functional dissection of the plasma corona of $\mathrm{SiO}_{2}-\mathrm{NPs}$ spots histidine rich glycoprotein as a major player able to hamper nanoparticle capture by macrophages. Nanoscale 7, 17710-17728 (2015).

15. Lundqvist, M. et al. Nanoparticle size and surface properties determine the protein corona with possible implications for biological impacts. Proc. Natl Acad. Sci. USA 105, 14265-14270 (2008).

16. Eigenheer, R. et al. Silver nanoparticle protein corona composition compared across engineered particle properties and environmentally relevant reaction conditions. Environ. Sci. Nano 1, 238-247 (2014) 
17. Nel, A. E. et al. Understanding the biophysicochemical interactions at the nano-bio interface. Nat. Mater. 8, 543-557 (2009).

18. Tenzer, S. et al. Nanoparticle size is a critical physic-chemical determinant of the human blood plasma corona: a comprehensive quantitative proteomic analysis. ACS Nano 5, 7155-7167 (2011).

19. Deng, Z. J. et al. Differential plasma protein binding to metal oxide nanoparticles. Nanotechnology 20, 455101-455109 (2009).

20. Walkey, C. D. \& Chan, W. C. W. Understanding and controlling the interaction of nanomaterials with proteins in physiological environment. Chem. Soc. Rev. 41, 2780-2799 (2012).

21. Lesniak, A. et al. Effects of the presence or absence of a protein corona on silica nanoparticle uptake and impact on cells. ACS Nano 6, 5845-5857 (2012).

22. Liu, R., Jiang, W., Walkey, C. D., Chan, W. C. W. \& Cohen, Y. Prediction of nanoparticles-cell association based on corona proteins and physicochemical properties. Nanoscale 7, 9664-9675 (2015).

23. Setyawati, M. I., Tay, C. Y., Docter, D., Stauber, R. H. \& Leond, D. T. Understanding and exploiting nanoparticles' intimacy with the blood vessel and blood. Chem. Soc. Rev. 44, 8174-8199 (2015).

24. Miclăuş, T., Bochenkov, V. E., Ogaki, R., Howard, K. A. \& Sutherland, D. S. Spatial mapping and quantification of soft and hard protein coronas at silver nanocubes. Nano Lett. 14, 2086-2093 (2014).

25. Beer, C., Foldbjerg, R., Hayashi, Y., Sutherland, D. S. \& Autrup, H. Toxicity of silver nanoparticles - nanoparticle or silver ion? Toxicol. Lett. 208, 286-292 (2012).

26. Foldbjerg, R. et al. Silver nanoparticles - wolves in sheep's clothing? Toxicol. Res 4, 563-575 (2015)

27. Gliga, A. R., Skoglund, S., Wallinder, I. O., Fadeel, B. \& Karlsson, H. L. Size-dependent cytotoxicity of silver nanoparticles in human lung cells: the role of cellular uptake, agglomeration and Ag release. Part. Fibre. Toxicol 11, 11-27 (2014).

28. Johnston, H. J. et al. A review of the in vivo and in vitro toxicity of silver and gold particulates: particle attributes and biological mechanism responsible for the observed toxicity. Crit. Rev. Toxicol. 40, 328-346 (2010).

29. Henglein, A. Colloidal silver nanoparticles: photochemical preparation and interaction with $\mathrm{O}_{2}, \mathrm{CCl}_{4}$, and some metal ions. Chem. Mater. 10, 444-450 (1998).

30. Lok, C.-N. et al. Silver nanoparticles: partial oxidation and antibacterial activities. J. Biol. Inorg. Chem. 12, 527-534 (2007).

31. Sotiriou, G. A., Meyer, A., Knijnenburg, J. T. N., Panke, S. \& Pratsinis, S. E. Quantifying the origin of released $\mathrm{Ag}^{+}$ions from nanosilver. Langmuir 28, 15929-15936 (2012).

32. Liu, J. \& Hurt, R. H. Ion release kinetics and particle persistence in aqueous nano-silver colloids. Environ. Sci. Technol. 44, 2169-2175 (2010).

33. Ma, R. et al. Size-controlled dissolution of organic-coated silver nanoparticles. Environ. Sci. Technol. 46, 752-759 (2012)

34. Liu, J., Pennell, K. G. \& Hurt, R. H. Kinetics and mechanism of nanosilver oxysulfidation. Environ. Sci. Technol. 45, 7345-7353 (2011).

35. Reinsch, B. C. et al. Sulfidation of silver nanoparticles decreases Escherichia coli growth inhibition. Environ. Sci. Technol. 46, 6992-7000 (2012).

36. Levard, C. et al. Sulfidation of silver nanoparticles: natural antidote to their toxicity. Environ. Sci. Technol. 47, 13440-13448 (2013).

37. Devi, G. P. et al. Sulfidation of silver nanoparticles reduces its toxicity in zebrafish. Aquat. Toxicol. 158, 149-156 (2015).

38. Starnes, D. L. et al. Impact of sulfidation on the bioavailability and toxicity of silver nanoparticles to Caenorhabditis elegans. Environ. Pollut. 196, 239-246 (2015).

39. Kim, B., Park, C.-S., Murayama, S. \& Hochella, Jr. M. F. Discovery and characterization of silver sulfide nanoparticles in final sewage sludge products. Environ. Sci. Technol. 44, 7509-7514 (2010).

40. Kent, R. D., Oser, J. G. \& Vikesland, P. J. Controlled evaluation of silver nanoparticle sulfidation in full-scale wastewater treatment plant. Environ. Sci. Technol. 48, 8564-8572 (2014).

41. Thalmann, B., Voegelin, A., Sinnet, B., Morgenroth, E. \& Kaegi, R. Sulfidation kinetics of silver nanoparticles reacted with metal sulfides. Environ. Sci. Technol. 48, 4885-4892 (2014).

42. Yu, S.-J., Yin, Y.-G., Chao, J.-B., Shen, M.-H. \& Liu, J.-F. Highly dynamic PVP-coated silver nanoparticles in aquatic environments: chemical and morphology change induced by oxidation of $\mathrm{Ag}^{0}$ and reduction of $\mathrm{Ag}^{+}$. Environ. Sci. Technol. 48, 403-411 (2014)

43. Liu, J., Sonshine, D. A., Shervani, S. \& Hurt, R. H. Controlled release of biologically active silver from nanosilver surfaces. ACS Nano 4, 6903-6913 (2010).

44. Gondikas, A. P. et al. Cysteine-induced modifications of zero-valent silver nanomaterials: implications for particles surface chemistry, aggregation, dissolution, and silver speciation. Environ. Sci. Technol. 46, 7037-7045 (2012).

45. Jiang, X. et al. Fast intracellular dissolution and persistent cellular uptake of silver nanoparticles in $\mathrm{CHO}-\mathrm{K} 1$ cells: implication for cytotoxicity. Nanotoxicology 9, 181-189 (2015).
46. Wang, L. et al. Use of synchrotron radiation-analytical techniques to reveal chemical origin of silver-nanoparticle cytotoxicity. ACS Nano 9, 6532-6547 (2015).

47. Chen, S. et al. Sulfidation of silver nanowires inside human alveolar epithelia cells: a potential detoxification mechanism. Nanoscale 5, 9839-9847 (2013).

48. Chen, S. et al. High-resolution analytical electron microscopy reveals cell culture media-induced changes to the chemistry of silver nanowires. Environ. Sci. Technol. 47, 13813-13821 (2013).

49. Choi, O. et al. Role of sulfide and ligand strength in controlling nanosilver toxicity. Water. Res 43, 1879-1886 (2009).

50. Bianchini, A. et al. Evaluation of the effect of reactive sulfide on the acute toxicity of silver (I) to Daphnia magna. Part 2: toxicity results. Environ. Toxicol. Chem. 21, 1294-1300 (2002).

51. Mann, R. M., Ernste, M. J., Bell, R. A., Kramer, J. R. \& Wood, C. M. Evaluation of the protective effects of reactive sulfide on the acute toxicity of silver to rainbow trout (Oncorhynchus Mykiss). Enviro. Toxicol. Chem 23, 1204-1210 (2004).

52. Selected Powder Diffraction Data for Metals \& Alloys Data Book. 1st edn. vol. 1JCPDS International Center for Diffraction Data, 1982).

53. Cia, X., Zeng, J., Zhang, Q., Moran, C. H. \& Xia, Y. Recent developments in shape-controlled synthesis of silver nanocrystals. J. Phys. Chem. C 116, 21647-21656 (2012).

54. Wang, Y., Zheng, Y., Huang, C. Z. \& Xia, Y. Synthesis of Ag nanocubes 18-32 $\mathrm{nm}$ in edge length: the effects of polyol on reduction kinetics, size control and reproducibility. J. Am. Chem. Soc. 135, 1941-1951 (2013).

55. Elechiguerra, J. L. et al. Corrosion at the nanoscale: the case of silver nanowires and nanoparticles. Chem. Mater. 17, 6042-6052 (2005).

56. El-Khairy, L., Ueland, P. M., Refsum, H., Graham, I. M. \& Vollset, S. E. Plasma total cysteine as a risk factor for vascular disease. Circulation 103, 2544-2549 (2001).

57. Salemi, G. et al. Blood levels of homocysteine, cysteine, glutathione, folic acid, and vitamin $\mathrm{B}_{12}$ in the acute phase of atherothrombosis stroke. Neural. Sci 30, 361-364 (2009).

58. Levard, C., Hotze, E. M., Lowry, G. V. \& Brown, Jr. G. E. Environmental transformations of silver nanoparticles: Impact on stability and toxicity. Environ. Sci. Technol. 46, 6900-6914 (2012).

59. Bopst, M., Haas, C., Car, B. \& Engster, H. P. The combined inactivation of tumor necrosis factor and interleukin-6 prevents induction of the major acute phase proteins by endotoxin. Eur. J. Immunol. 28, 4130-4137 (1998).

60. Martinez-Gutierrez, F. et al. Antibacterial activity, inflammatory response, coagulation and cytotoxicity effects of silver nanoparticles. Nanomed. Nanotechnol 8, 328-336 (2012).

61. Park, M.V.D.Z. et al. The effect of particle size on the cytotoxicity, inflammation, developmental toxicity and genotoxicity of silver nanoparticles. Biomaterials 32, 9810-9817 (2011)

62. Driscoll, K. E. TNF $\alpha$ and MIP-2 production: role in particle-induced inflammation and regulation by oxidative stress. Toxicol. Lett. 112-113, 177-184 (2000)

63. Zhang, Q., Li, W., Wen, L.-P., Chen, J. \& Xia, Y. Facile synthesis of Ag nanocubes of 30 to $70 \mathrm{~nm}$ in edge length with $\mathrm{CF}_{3} \mathrm{COOAg}$ as a precursor. Chem. Eur. J 16, 10234-10239 (2010).

64. Wiley, B., Sun, Y., Mayers, B. \& Xia, Y. Shape-controlled synthesis of metal nanoparticles: the case of silver. Chem. Eur. J 11, 454-463 (2005).

65. Foldbjerg, R., Dang, D. A. \& Autrup, H. Cytotoxicity and genotoxicity of silver nanoparticles in the human lung cancer cell line, A549. Arch. Toxicol. 85, 743-750 (2011).

66. Reidy, B., Haase, A., Luch, A., Dawson, K. A. \& Lynch, I. Mechanism of silver nanoparticle release, transformation and toxicity: a critical review of current knowledge and recommendations for future studies and applications. Materials 6, 2295-2350 (2013).

67. Helmlinger, J. et al. Silver nanoparticles with different size and shape: equal cytotoxicity, but different antibacterial effects. RSC Adv 6, 18490-18501 (2016).

68. Foldbjerg, R. et al. Global gene expression profiling of human lung epithelial cells after exposure to nanosilver. Toxicol. Sci. 130, 145-157 (2012).

69. Jiang, X. et al. Multi-platform genotoxicity analysis of silver nanoparticles in the model cell line CHO-K1. Toxicol. Lett. 222, 55-63 (2013).

\section{Acknowledgements}

This work was funded through a Danish strategic research council grant (SIDANA 09067185). The research leading to these results has received funding from the European Community's Seventh Framework Programme under grant agreement no 602699 (DIREKT). V.E.B. acknowledges the support from RFBR grant 15-03-99582. We thank Mauro Porcu from FEI for his help with the preliminary STEM study.

\section{Author contributions}

T.M. and D.S.S. designed the experiments, except for the cell studies. T.M., C.B. and D.S.S. designed the toxicology experiments and C.B. performed them. T.M. performed all 
other experiments except FDTD simulations (V.E.B.), mass spectrometry (C.S. and J.E.) and EDS, elemental mapping and TEM diffraction (T.M and J.C). T.M and D.S.S. analysed the data, except for EDS and diffraction (T.M., J.C. and D.S.S), mass spectrometry (T.M., C.S. and J.E.), toxicology (T.M., C.B. and D.S.S.) and simulations data (T.M, V.E.B.). T.M and D.S.S. wrote the manuscript and the Supplementary Information.

\section{Additional information}

Supplementary Information accompanies this paper at http://www.nature.com/ naturecommunications

Competing financial interests: The authors declare no competing financial interests.
Reprints and permission information is available online at http://npg.nature.com/ reprintsandpermissions/

How to cite this article: Miclăuş, T. et al. Dynamic protein coronas revealed as a modulator of silver nanoparticle sulphidation in vitro. Nat. Commun. 7:11770 doi: $10.1038 /$ ncomms11770 (2016).

\section{(c) (1)}

This work is licensed under a Creative Commons Attribution 4.0

International License. The images or other third party material in this article are included in the article's Creative Commons license, unless indicated otherwise in the credit line; if the material is not included under the Creative Commons license, users will need to obtain permission from the license holder to reproduce the material. To view a copy of this license, visit http://creativecommons.org/licenses/by/4.0/ 